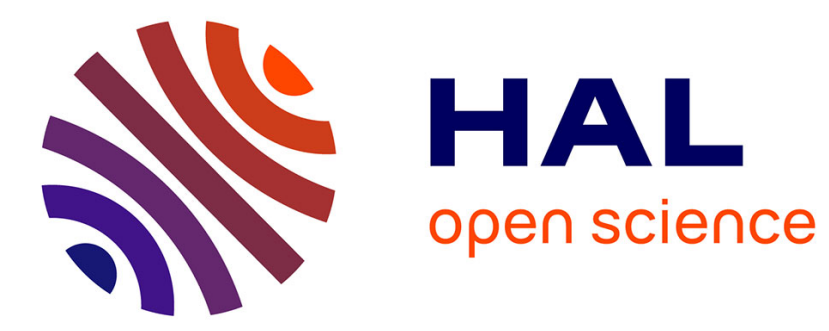

\title{
Evaluation of Stresses in a Two-Layer Co-Extruded LDPE Melt Blown Film
}

E. Gamache, Jean-François Agassant, Y. Demay, P. G. Lafleur

\section{To cite this version:}

E. Gamache, Jean-François Agassant, Y. Demay, P. G. Lafleur. Evaluation of Stresses in a Two-Layer Co-Extruded LDPE Melt Blown Film. Journal of Plastic Film and Sheeting, 2005, 21 (2), pp.127-144. 10.1177/8756087905057006 . hal-00572061

\section{HAL Id: hal-00572061 https://hal.science/hal-00572061}

Submitted on 1 Mar 2011

HAL is a multi-disciplinary open access archive for the deposit and dissemination of scientific research documents, whether they are published or not. The documents may come from teaching and research institutions in France or abroad, or from public or private research centers.
L'archive ouverte pluridisciplinaire HAL, est destinée au dépôt et à la diffusion de documents scientifiques de niveau recherche, publiés ou non, émanant des établissements d'enseignement et de recherche français ou étrangers, des laboratoires publics ou privés. 


\title{
Evaluation of Stresses in a Two-layer Co-eXtruded LDPE Melt Blown Film*
}

\author{
E. Gamache, ${ }^{1}$ J.-F. Agassant, ${ }^{2}$ Y. Demay ${ }^{2}$ and P. G. Lafleur ${ }^{1, \uparrow}$ \\ ${ }^{1}$ Ecole Polytechnique de Montreal \\ CRASP, Chemical Engineering Department \\ C.P. 6079, Succ. Centre-ville \\ Montréal, Québec, Canada H3C $3 A 7$ \\ ${ }^{2}$ École des Mines de Paris \\ CEMEF, 1, rue Claude Daunesse BP207 F-06904 \\ Sophia Antipolis Cedex, France
}

\begin{abstract}
Despite the fast growth of co-extruded film production, little research work has been devoted to this process. Films of LDPE, ULDPE, LDPE/ULDPE and ULDPE/LDPE were produced at various processing conditions. A continuous experimental set up was used to evaluate the in-plane birefringence during bubble formation. The data collected were used to derive the axial and transverse stresses. A non-isothermal Newtonian model that allows the determination of the kinematics and dynamics of the two-layer film blowing process was then used to calculate the axial and transverse stress. Generally the calculated stresses are in agreement with the experimental values.
\end{abstract}

KEY WORDS: film blowing, co-extruded, birefringence, stress, numerical modeling.

\section{INTRODUCTION}

7 HE FILM BLOWING process has been used to produce polymer films since 1940. It is one of the most widely used polymer processing technologies. A thermoplastic melt, typically a polyolefin, is extruded through an annular die at a constant output as illustrated in Figure 1. The molten tube leaving the die is pulled upwards by the nip rolls. Concurrently to the axial drawing, air is introduced into the tube

\footnotetext{
*This article was originally presented at the Films and Fibers 2004 Symposium of the National Research Council of Canada, which was held in Boucherville, Quebec, Canada in September 2004.

†Author to whom correspondence should be addressed. E-mail: pierre.lafleur@polymtl.ca
} 


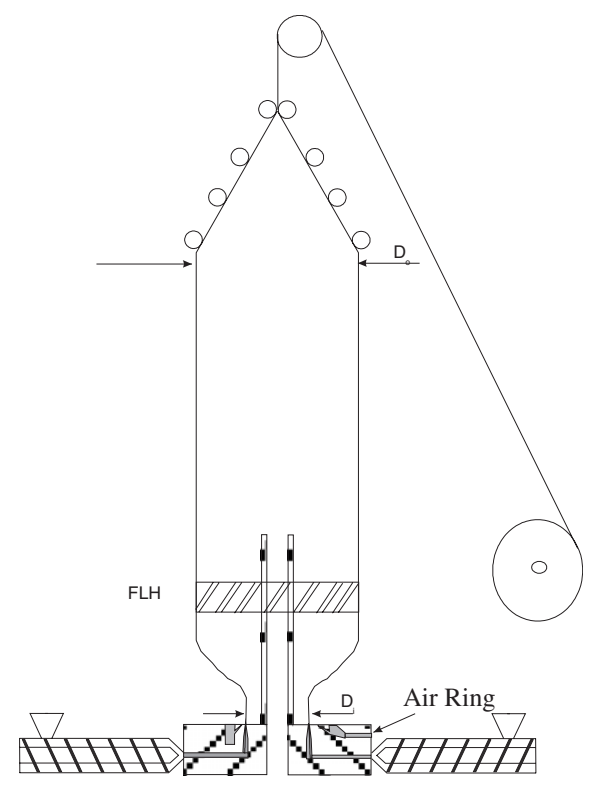

Figure 1. General view of the co-extruded film blowing process.

through an opening in the center of the die to inflate the tube and produce a bubble. The inflation of the tube produces a film that is inherently biaxially stretched. The take up ratio (TUR) is defined as the speed of the film at the nip rolls over the speed of the polymer melt at the die exit. The blow up ratio (BUR) is defined as the final bubble diameter over the diameter of the die. Simultaneous to the stretching, air is projected at high speed on the bubble outer surface in order to increase the cooling rate and the overall output. The position at which the melt crystallizes is named the frost line height or FLH. The FLH can be used to evaluate the cooling rate of the film. It is possible to increase the overall cooling rate by adding an internal bubble cooling system (IBC) to the film blowing line. Despite the complex interaction between the process parameters, the film blowing process is interesting because of the wide range of physical and mechanical properties of the film produced. To produce co-extruded films, which can be composed of up to eleven layers, additional extruders are added to feed the die, but the blowing process itself remains unchanged. The different experimental aspects of the film blowing process have been widely covered in literature. For example, Ghaneh-Fard et al. [1] used birefringence to determine the stress level in the melt zone and the total orientation 
in solidified LLDPE blown film. Babel and Campbell [2] reported a correlation between the amount of plastic strain and the ultimate physical properties of the film. Kuijk et al. [3] were able to demonstrate that mechanical properties such as machine and transverse direction moduli, elongation at break, tensile strength yield stress and tear resistance, correlate well with the stress level in the polymer melt at the freeze line. So the determination of the stress generated during the blown film process, either from experimental data or from numerical calculation, could give us insight into the properties of the film produced. Furthermore, Han and Park [4] documented the various types of instabilities occurring in the process. Cao and Campbell [5] showed that the predicted shape of the bubble was more adequately represented when the air ring effect on the blown film dynamics was taken into account.

The first attempt to develop a model that will predict efficiently the behavior of the film blowing process was made by Pearson and Petrie $[6,7]$. They used a Newtonian rheological behavior under isothermal conditions to evaluate the kinematics and stresses using a membrane approximation. Subsequently, Petrie [8] improved that first approach by using a viscoelastic rheological model. Heat transfer was included for the first time in the simulation by Han and Park [9], but they did not take into account the crystallization process. More recently, Andre [10] elaborated steady state non-isothermal Newtonian and viscoelastic models in which the position of the frost line was obtained by calculation. He showed that the calculated bubble shape depends strongly on the initial angle of the bubble at the die exit. This fact has been hidden in previous work. The existence of multiple solutions for the bubble shape and of an unattainable zone was underlined in the viscoelastic case. This signifies that viscoelastic results can be obtained only for cases close to a Newtonian behavior (when the Deborah number is small). This means that the addition of viscoelasticity to the model leads to relatively small improvement to the numerical results because of these numerical constraints. Laffargue [11] used a technique initially presented by Housiadas and Tsamopoulos $[12,13]$ to express mechanical and thermal balance equations in a fixed coordinates system. Using this method, it is possible to develop a set of equations at various orders of magnitude of a small parameter (the ratio of the initial thickness of the film over the initial radius of the bubble). This method allows Laffargue et al. to solve the film blowing process in steady state but also in unsteady state conditions. It did not take into account the crystallization process and the bubble temperature profile that was imposed between the die exit and the FLH. 
Surprisingly, despite the fast growth of co-extruded film production, relatively few studies have been done to numerically describe this process. The main effort has been done by Yoon and Park [14] in 1992 who studied a bicomponent film composed of a Newtonian inner layer and an upper-convected Maxwell outer layer. They illustrated the effect of the relaxation time and the flow rate ratio on the bubble shape. The main drawback of their work is that the blown film process is supposed to be isothermal. Recently, Gamache [15] developed a model to take into account the dynamics, kinematics, and heat transfer occurring in the coextruded film blowing process. The model was based on the single layer film blowing model developed by Laffargue [11].

Our goal is to evaluate the birefringence in a two-layer blown film in order to determine the stress profiles in the polymer. This will allow us to determine the effect of the flow rate of each layer, of the layer positioning, and of the processing conditions on the axial and transverse stress profile. These data will then be used to validate a Newtonian non-isothermal numerical resolution scheme that was developed previously.

\section{EXPERIMENTAL PROCEDURE}

The rheological characterization of the polymers used (LDPE Dow 609a and ULDPE Attane 4201) was carried out using a SR5000 Rheometric Scientific rheometer at a deformation rate between 0.628 and $62.8 \mathrm{rad} / \mathrm{s}$ and at various temperatures. The activation energy, $E_{\mathrm{a}}$ of LDPE and ULDPE was respectively, 44 and $26 \mathrm{~kJ} / \mathrm{mol}$. The viscosity of these two materials at the Newtonian plateau at the reference temperature $T_{\mathrm{r}}=220^{\circ} \mathrm{C}$ was found to be respectively 12,000 and $6,200 \mathrm{~Pa}$ s. A DSC analysis was also performed on both materials to obtain their respective crystallization temperatures and enthalpy. The crystallization temperature is used as a boundary condition in our calculation. The thermal dependence of viscosity in our calculation can be taken into account with the following Arrhenius function:

$$
\eta(T)=e^{\left(E_{\mathrm{a}} / R\right)\left[(1 / T)-\left(1 / T_{\mathrm{r}}\right)\right]} \eta\left(T_{\mathrm{r}}\right)
$$

Monolayer and two-layer films were produced on a Brampton co-extruded blown film line. The die had an external diameter of $101.6 \mathrm{~mm}$ and a gap of $1.1 \mathrm{~mm}$. The flow rate of the extruders was controlled with gravimetric balance. The total flow rate was kept constant at $7.2 \mathrm{~kg} / \mathrm{h}$ in all cases. The die temperature was set to 
$230^{\circ} \mathrm{C}$ and the cooling air flow rate was kept at a constant value for all experiments. The process parameters investigated were:

- take up ratio

- blow up ratio

- layer position

- flow rate ratio of each layer in the film.

The technique presented by Ghaneh Fard et al. [1] to measure online birefringence was slightly modified in order to be able to measure birefringence in a continuous mode. For this purpose we positioned our laser (A) $(632.8 \mathrm{~nm})$ and detector (B) on the moving tower (C) of the blown film line as shown in Figure 2. The axial position of the light source was evaluated from the initial and final positions of the tower and the acquisition time. At least three series of measurements were done for each processing condition studied. Repeatability of the birefringence data was found to be excellent. At the end of the last birefringence scan, the bubble was cooled down by simultaneously stopping extruders and the nip rolls and by increasing the cooling air flow rate. This allowed us to obtain a solid shell of the bubble on which it

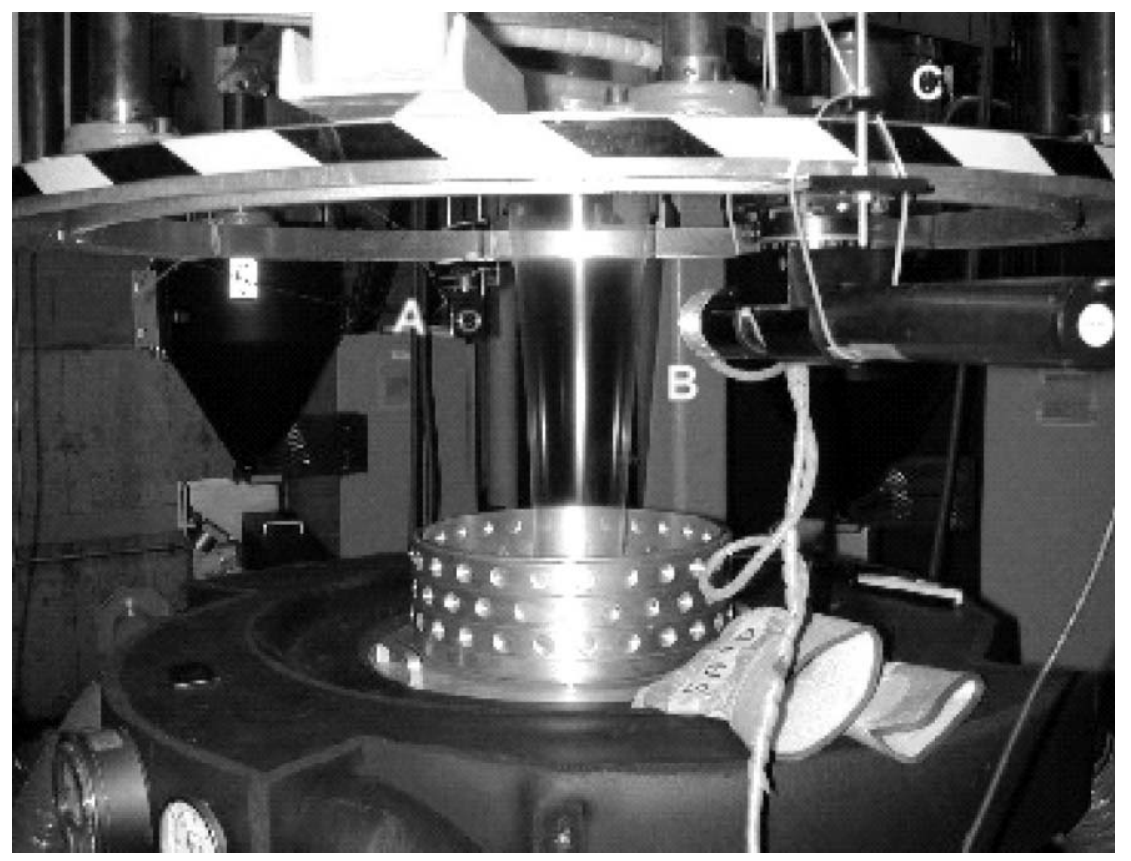

Figure 2. Experimental setup. 
was possible to evaluate the film radius and thickness as a function of axial position. The pressure inside the bubble was also measured with a manometer connected to the bubble inflation air line. These values are necessary to derive the stress profiles from the birefringence data.

It is possible to derive birefringence from the measured retardance $\delta(z)$, which is the time delay between the ordinary and extraordinary light beam generated in an anisotropic material using the following relation:

where

$$
\Delta_{3} n(z)=n_{11}(z)-n_{33}(z)=\frac{\delta(z) \lambda \cos \left(\theta_{\mathrm{r}}(z)\right)}{2 \pi h(z)}
$$

$$
\begin{aligned}
h & =\text { film thickness } \\
\lambda & =\text { light source wavelength } \\
\Delta n(z) & =\text { birefringence } \\
\theta_{r} & =\text { refraction angle }
\end{aligned}
$$

It is possible to obtain the refraction angle from the Snell law:

$$
\sin \theta_{\mathrm{r}}=\frac{\sin \theta_{\mathrm{i}}}{n}
$$

where

$$
\begin{aligned}
n & =\text { refractive index } \\
\theta_{i} & =\text { inflation angle evaluated from the frozen shell of the bubble }
\end{aligned}
$$

It is then possible to link the birefringence to the difference between the axial and transverse stresses.

$$
n_{11}(z)-n_{33}(z)=C\left(\sigma_{11}(z)-\sigma_{33}(z)\right)
$$

The Brewster coefficient $C$ is equal to $2.1 \times 10^{-9} \mathrm{~m}^{2} \mathrm{~N}^{-1}$ for polyethylene. The actual value of the axial and transverse stresses can be evaluated by combining the previous equations with the following relations deduced from the Pearson and Petrie model [6,7]:

$$
\frac{\Delta P}{h(z)}=\frac{\sigma_{11}(z)}{R_{1}(z)}+\frac{\sigma_{33}(z)}{R_{3}(z)}-\rho g \sin \theta
$$

where $R_{1}$ and $R_{3}$ are the local radius of curvature

$$
\begin{aligned}
& R_{3}(z)=R(z) \sqrt{1+\left(\tan \theta_{\mathrm{i}}\right)^{2}} \\
& R_{1}(z)=\frac{-\left(1+\left(\tan \theta_{\mathrm{i}}\right)^{2}\right)^{3 / 2}}{\left(\mathrm{~d}^{2} r / \mathrm{d} z^{2}\right)(z)}
\end{aligned}
$$


From the radius profile of our frozen shell, it is possible to evaluate the inflation angle, the refraction angle, and the values of $R_{1}$ and $R_{3}$.

\section{RESULTS}

We produced bubbles at various take up ratios between 11 and 19, and at blow up ratios between 1.6 and 2.4, to cover a wide range of operating conditions. Figure 3 illustrates an experimental radius profile obtained for a monolayer LDPE film. The FLH of this bubble was approximately $0.9 \mathrm{~m}$. This is quite high for the film blowing process, but this is consistent with the very low air flow rate that we used in order to be able to measure birefringence on a wide axial position range. The simulation result (radius and temperature) shown in Figure 3 was obtained using the numerical model described in Gamache [15] by fitting on the heat transfer function. Because we kept the cooling air rate at a constant set point, we can assume that the convection heat transfer function that allowed us to describe the radius profile of this bubble remains valid for a range of other experimental cases. The heat transfer relation that allowed us to obtain these calculated results is illustrated in Figure 4, which also presents convective heat transfer of other authors compiled by Nagarajan and Campbell [16]. Our values are much lower than those

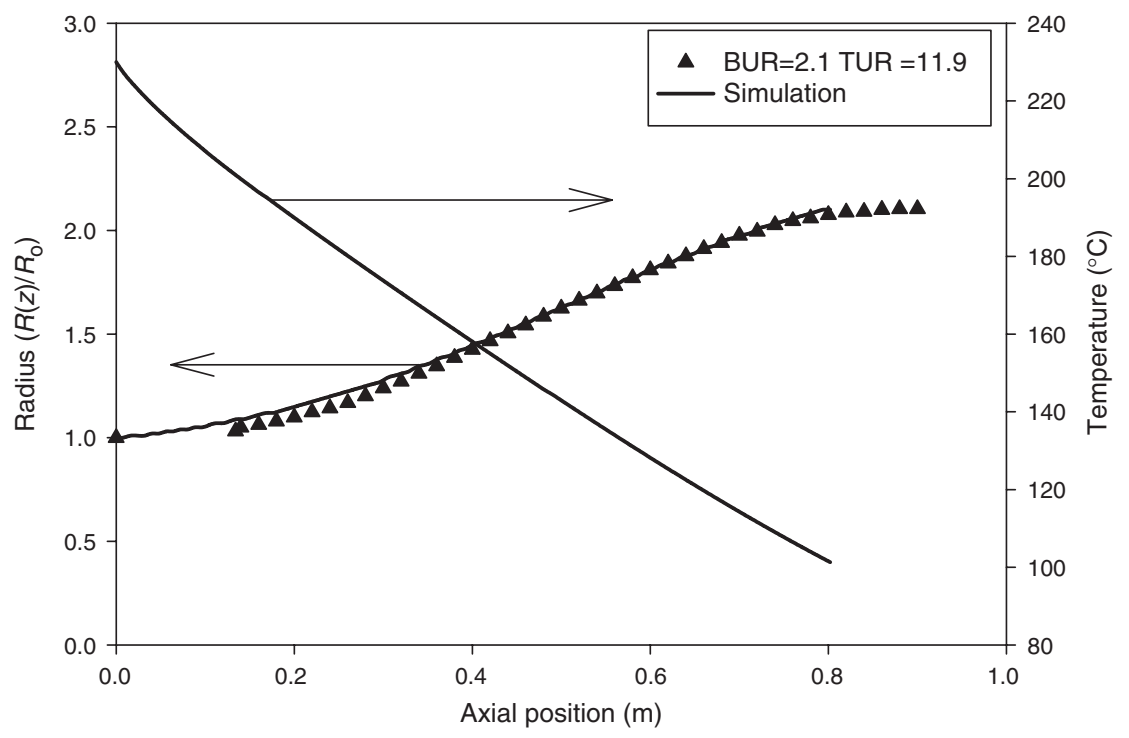

Figure 3. Calculated and experimental radius profile for LDPE monolayer film. 


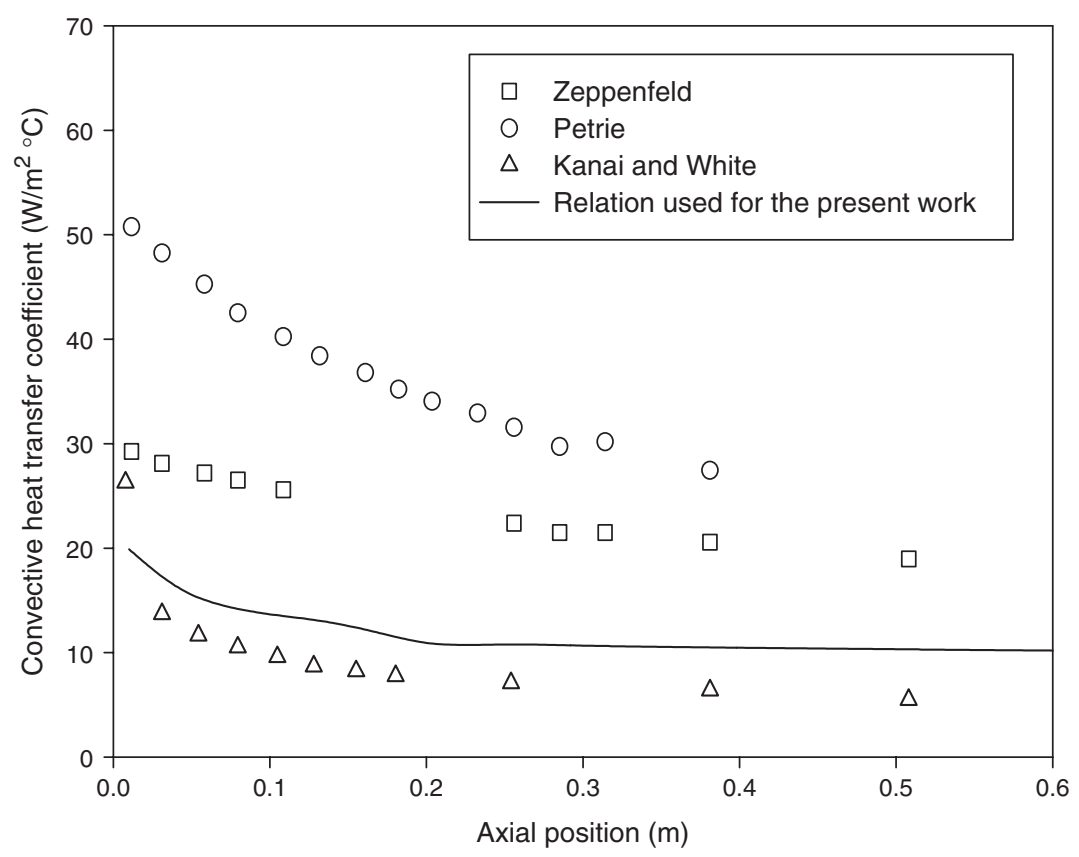

Figure 4. Heat transfer coefficient used in numerical simulation.

of Petrie [17] and Zeppenfeld [18]. This is not surprising because, as we stated previously, the cooling rate of the air ring was kept quite low. For every subsequent simulation, we will use the relation shown in Figure 4. This means that only the simulation results shown in Figure 3 are fitted results.

Figure 5 shows that the calculated results properly describe the experimental radius profile for the ULDPE monolayer film blown at other processing conditions than those shown previously. This means that the models that we developed allow us to describe the monolayer film blowing of both materials. The calculated temperature profiles illustrated in Figures 3 and 5 are quite similar to experimental data reported previously by Laffargue [11].

Figure 6 illustrates the influence of the LDPE position either on the inner layer (black) or on the outer layer (white), for a co-extruded film composed of LDPE and ULDPE, on the experimental radius profile of the co-extruded bubble. It is clear that the material position does not affect significantly the blowing process of the bubble. In addition, the 


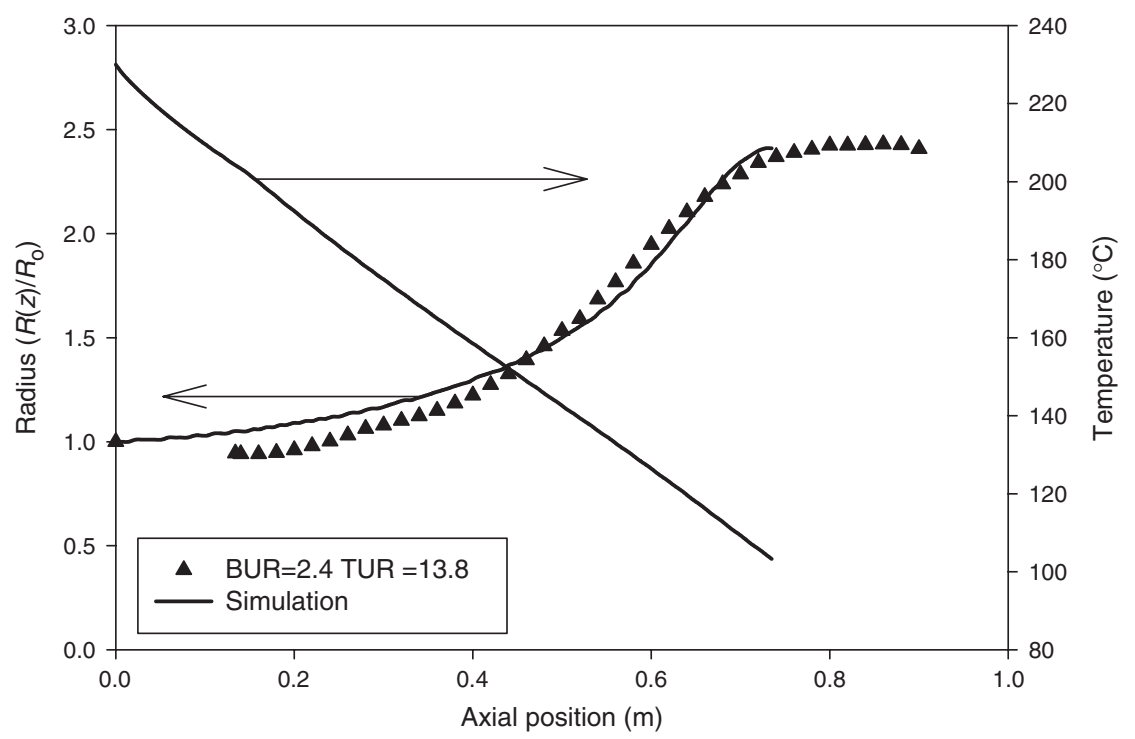

Figure 5. Calculated and experimental radius profile for ULDPE monolayer film.

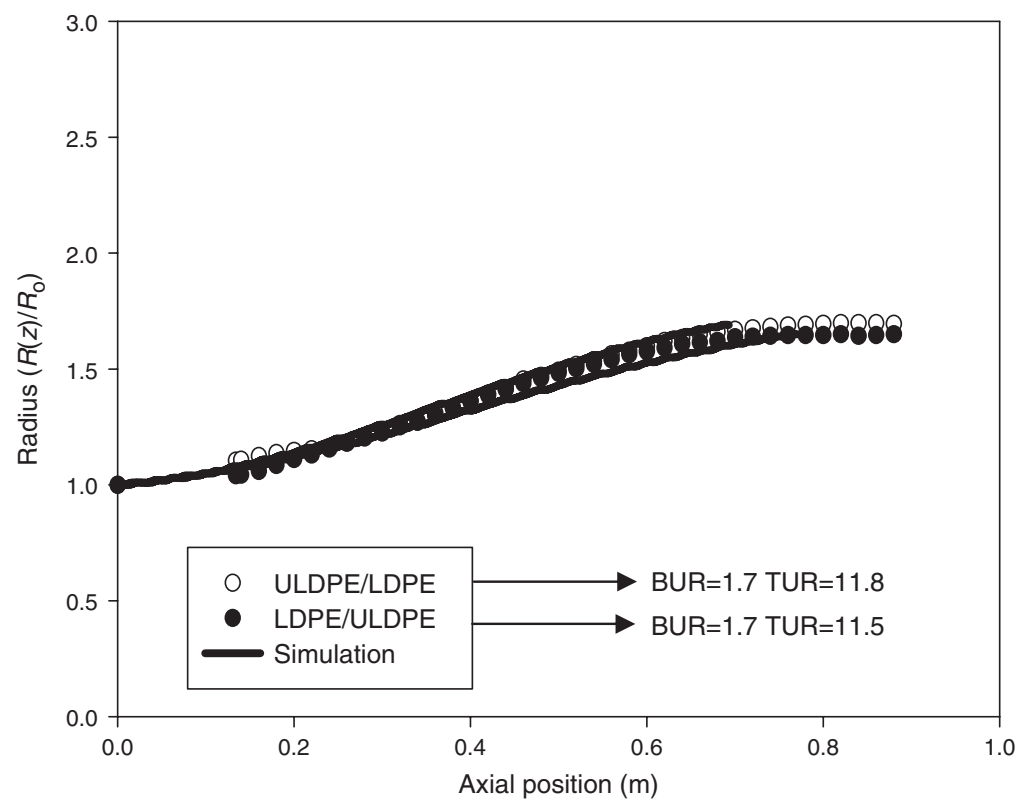

Figure 6. Experimental and calculated radius profile. Effect of material position. 


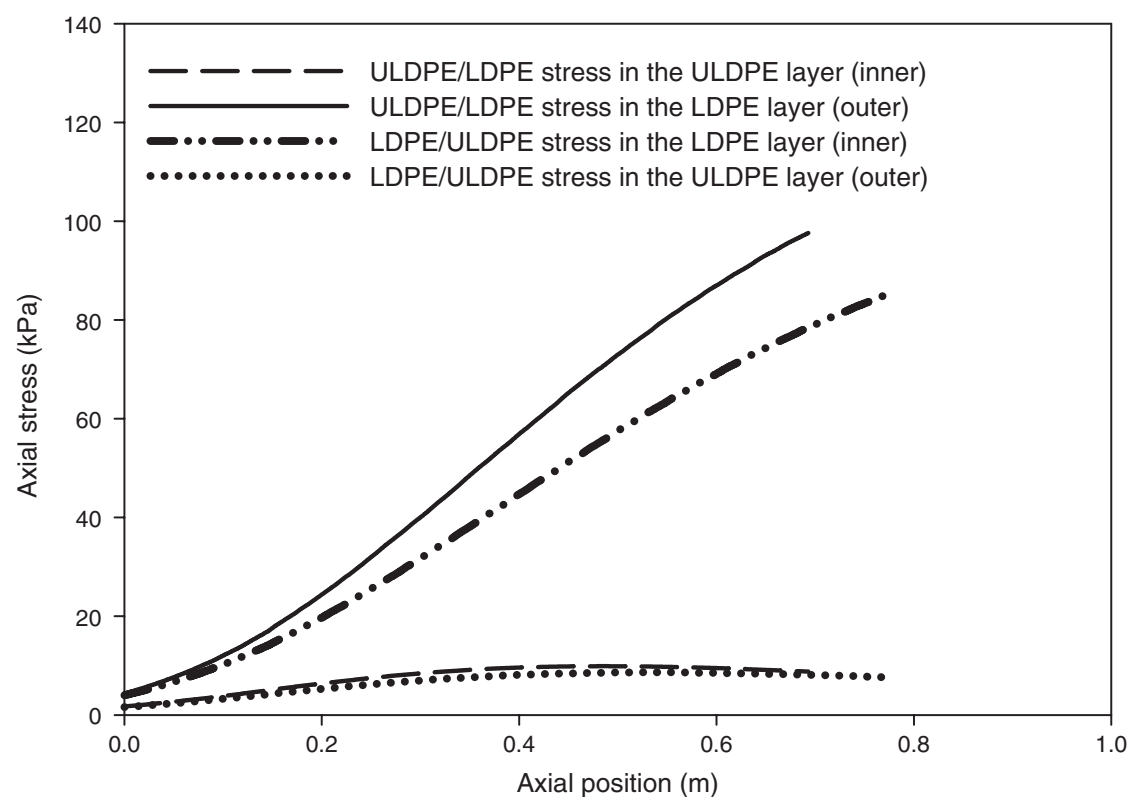

Figure 7. Calculated axial stress in each layer.

calculation results obtained with the convective heat transfer relation shown in Figure 4 are quite close to the experimental radius profiles.

Figure 7 illustrates the calculated axial stress generated in each layer as a function of material position. We observe that the calculated stress is always higher in the LDPE layer than in the ULDPE layer. This results from the fact that the LDPE layer is more viscous and has higher activation energy than the ULDPE. Basically, it means that the controlling material in this case is the LDPE. The magnitude of the force applied at the nip rolls will be mostly a function of the LDPE rheological properties. Because the experimental stress obtained from birefringence are averaged stresses in the film thickness, it is necessary to average also the calculated stress, if we want to compare experimental and calculated results.

Figure 8(a) and (b) illustrates the experimental and calculated average axial and transverse stress profiles. The experimental data show that a material can be located on the inner or outer layer without any effect on the properties of the film. The small difference that can be seen might be attributed to the fact that the take up ratio of the ULDPE/LDPE film is slightly higher than the take up ratio of the LDPE/ULDPE film (11.8 vs. 11.5). If identical process parameters, at the exception of materials 
Evaluation of Stresses in a Two-layer Co-extruded LDPE Film
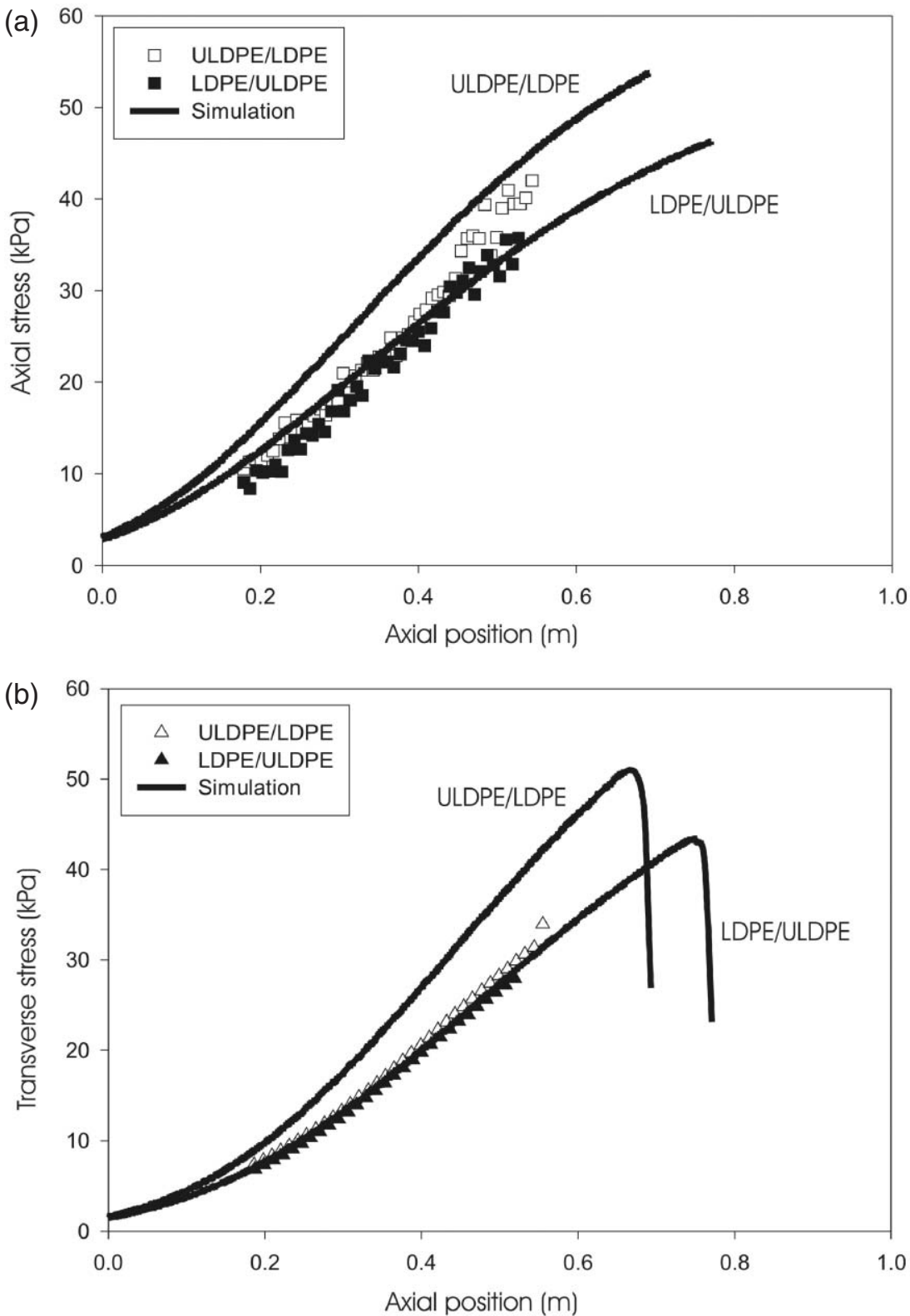

Figure 8. Experimental and calculated average axial and transverse stress: (a) axial stress and (b) transverse stress. 
position, are used in the calculation of ULDPE/LDPE and LDPE/ ULDPE films, the calculated average transverse and axial stresses and radius profiles are identical. The calculated results seem to describe properly the experimental data. The sharp fall off of the calculated transverse stress can be explained by the fact that it is partially dependent on the radial velocity of the bubble. When the bubble approaches the frost line, its radial velocity decreases suddenly, resulting in a sharp decrease in the transverse stress. Basically, at the end of the blowing process, the transverse stress at the frost line is mainly governed by the hydrostatic pressure in the bubble.

The next step was to study the influence of the blow up ratio on the radius profile (Figure 9). A high BUR leads to a lower FLH. This is consistent with results previously observed for single layer film blowing. An increase of BUR leads to a higher bubble surface, which in turn leads to an increase of the cooling rate, even if the cooling air flow rate remains constant, which finally leads to a lower FLH. In this figure it is possible to notice that the calculated results adequately fit the experimental data for the low blow up ratio. On the contrary, at a high blow up ratio, the calculated bubble shape (full line) is far from the experiment. Furthermore, it drastically overestimates the FLH position.

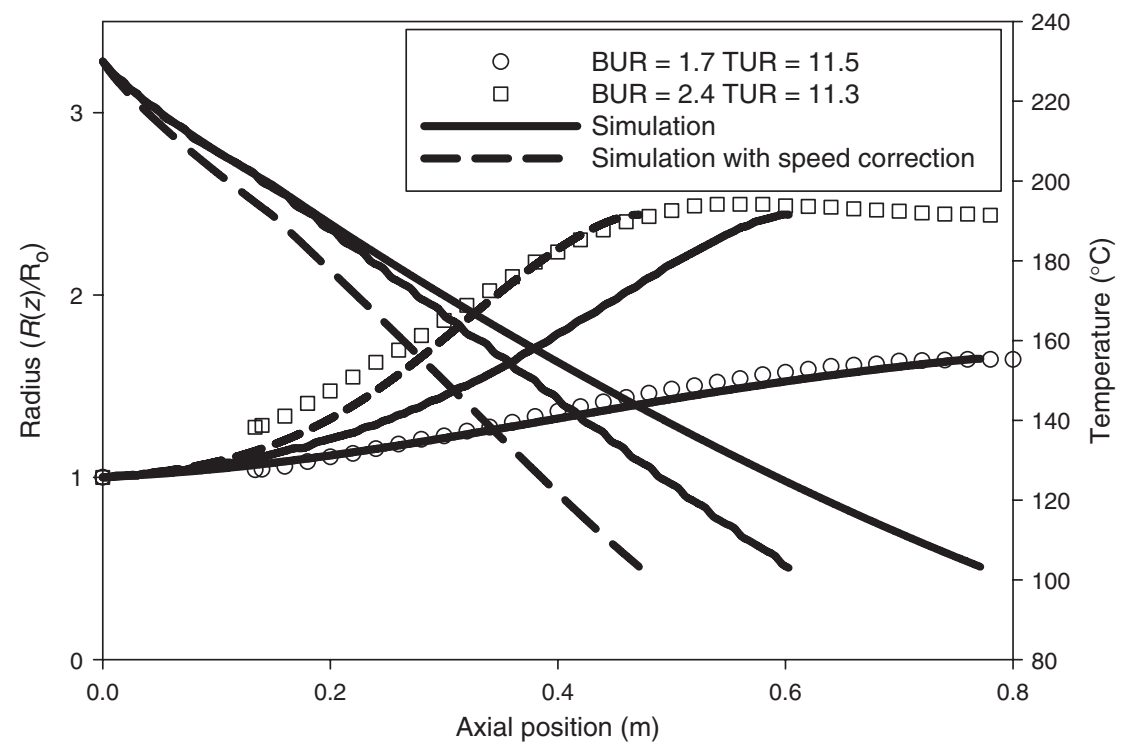

Figure 9. Experimental and calculated radius profile. Effect of blow up ratio (LDPE/ ULDPE). 
This discrepancy between the calculated and experimental results is caused by the fact that, despite the use of a constant air flow rate, the convective heat transfer coefficient does not remain constant when the bubble is subjected to a fast inflation. It is possible to observe on Figures 3, 5, and 6 that the bubble diameter at the air ring exit location is between 1 and 1.1. On Figure 10 it has a value of 1.3 . This means the area available for the cooling air to flow between the air ring and the bubble is smaller, which leads to a higher cooling air velocity. This fact has already been highlighted by Sidiroupoulos and Vlachopoulos [19,20], who conducted an extensive numerical study of the bubble cooling process. They were able to show that the air ring designs (single lip vs. dual lips) as well as the bubble shape affect quite strongly the air flow around the bubble. This has a significant impact on the convective behavior and on the pressure difference between the outer and inner side of the bubble. We must take this phenomenon into account if we want to describe the film blowing process properly.

The convective heat transfer can be related to the cooling fluid velocity through the following relation:

$$
h(z)=A\left(V_{\max }(z)\right)^{e}
$$

Zeppenfeld [18] and Kanai and White [21] reported value of $e$ to be equal to 0.8, while Menges and Predohl [22] and Petrie [17] reported a value of 1.5. $A$ is a constant, which differs from author to author.

An increase in the cooling air velocity will lead to an increase of the convective heat transfer coefficient. With the air ring geometry and a mass balance, it is possible to evaluate the velocity increase and then to deduce a corrected convective heat transfer coefficient valid for high blow up ratio. When this correction was applied (dashed line on Figure 9 ), the calculated bubble radius overlapped the experimental data for both materials. The numerical results following have been corrected when necessary.

Figure 10(a) and (b) show that an increase in the BUR leads to higher average axial and transverse stresses in the film. The amplitude and the slope of the profiles are strongly affected at the higher BUR. Both the axial and transverse stresses are increased by almost $300 \%$. This strong increase could potentially have a significant impact on the film's properties. The calculated stresses for the low BUR bubble are superimposed with experiments. A small difference between the calculated and experimental axial stress can be observed for the high blow up ratio, but the overall curve representation is still relevant. The discrepancy for the transverse stress is significant. 

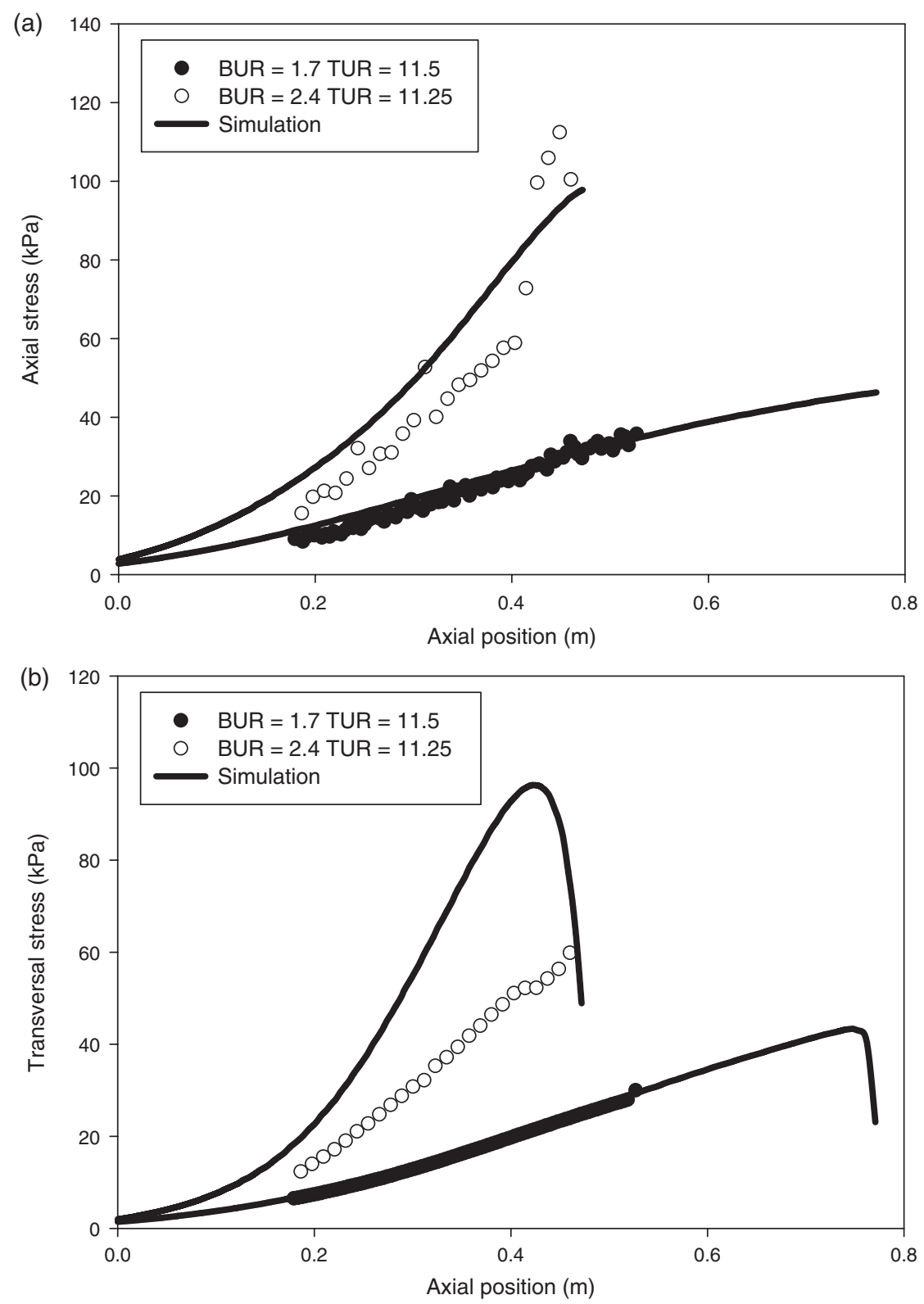

Figure 10. Experimental and calculated axial and transverse stress. Effect of BUR (LDPE/ULDPE): (a) axial stress and (b) transverse stress. 
Finally, Figure 11(a) illustrates the effect of two-layer film composition on the radius profile. The monolayer LDPE film blows slightly faster than the two-layer films. This is expected because, as we stated previously, the LDPE is the more viscous material. An increase in the amount of LDPE should generate higher stress, which in turn leads to a faster bubble blowing. The calculated results for the threefilm compositions are almost equivalent. The calculated LDPE monolayer film reaches its FLH a little faster than both two-layer films. In Figure 11(b), we observe a clear increase in the calculated and experimental axial stresses with the amount of LDPE in the film. The same pattern can be observed for the calculated transverse stresses on Figure 11(c), but this is not the case for the experimental values.

\section{CONCLUSION}

Birefringence measurements were made on monolayer and two-layer films of LDPE and ULDPE. An increase of TUR and BUR leads to an increase of the average axial and transverse stress in the monolayer and two-layer films. The polymer position in a two-layer film does not affect the bubble shape or stress profile. It seems that the stress in the film can be related to the amount of the $\mathrm{PE}$ which has a higher viscosity and activation energy.

The non-orthogonal mapping technique applied to the film blowing process and especially to the heat transfer equation allowed us to compute the bubble shape, average temperature profile and stress field for both the monolayer and two-layer blown film extrusion process. A heat transfer function, similar in shape to data previously published has been deduced from one reference experiment. This function was then applied to realize calculation at processing conditions (TUR and/or BUR) that are different from the reference experiment. Generally, for both the monolayer and two-layer films, the slope and the value of the calculated axial and transverse stress are approximately the same as the experimental ones. Nevertheless, at high TUR and BUR our model seems to overestimate the axial and transverse stresses.

It would be interesting now to evaluate film properties, such as impact strength, tear strength, and tensile strength, and to correlate those values to the axial and transverse stresses. This could lead to the development of films for specific use, by a modification of the process parameters. 

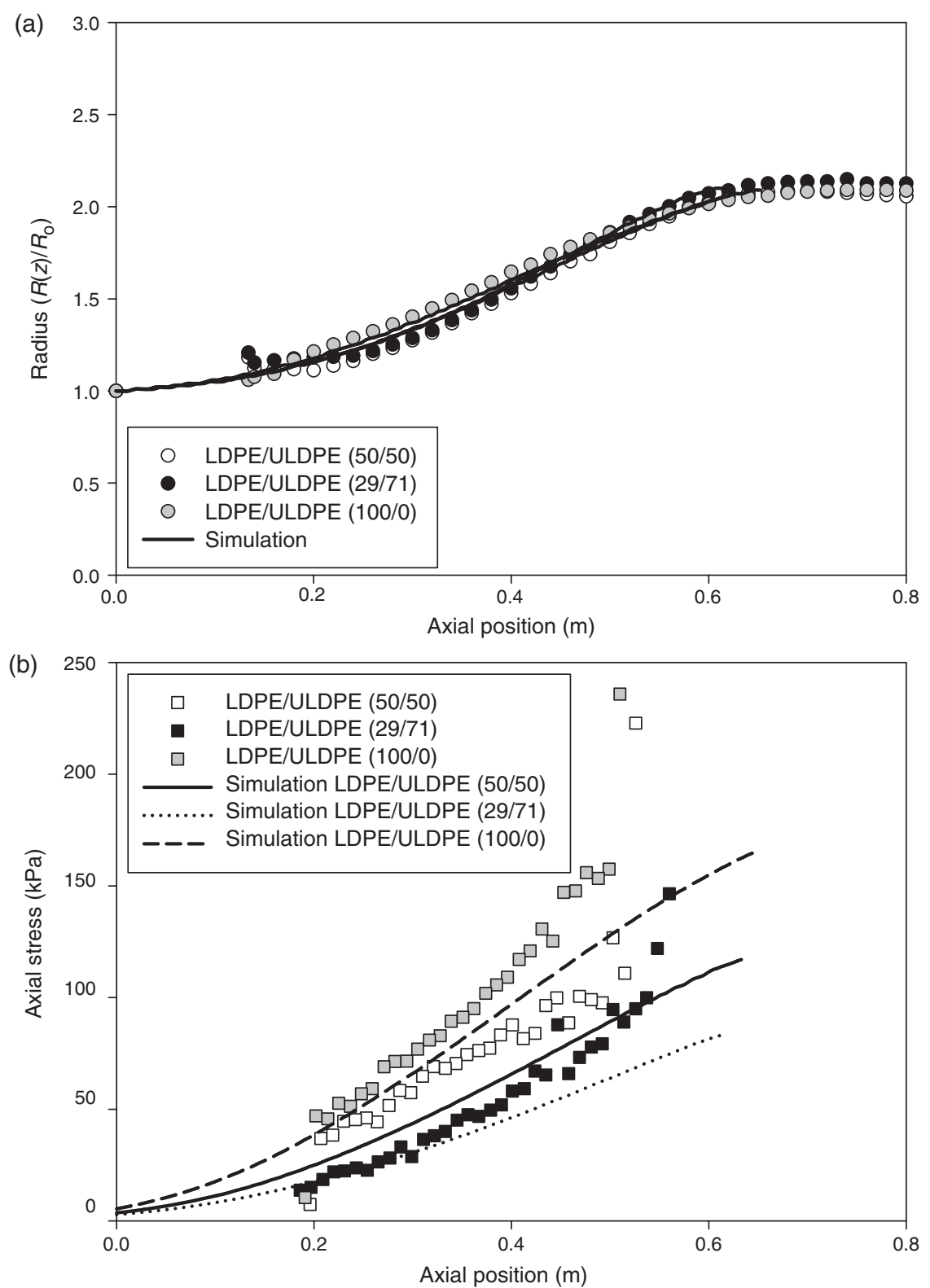

Figure 11. Effect of film composition. BUR $\approx 2.1$, TUR $\approx 16$. (a) Experimental and calculated radius profile; (b) experimental and calculated axial stress; and (c) experimental and calculated transverse stress. 


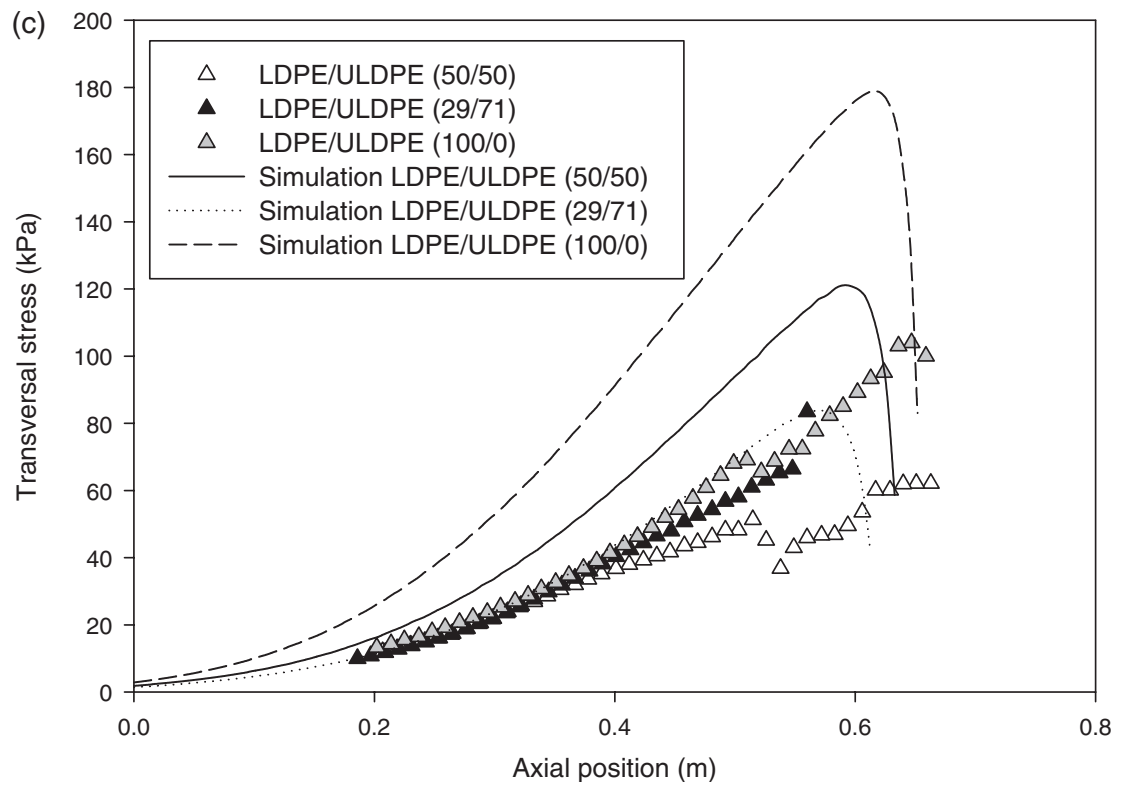

Figure 11. Continued.

\section{REFERENCES}

1. Ghaneh-Fard, A., Carreau, P.J. and Lafleur, P.G. (1997). On-Line Birefringence Measurement in Film Blowing of a Linear Low Density Polyethylene, Intern. Polymer Processing, XII(2): 136-146.

2. Babel, A.K. and Campbell, G.A. (1993). Correlating the Plastic Strain with the Properties of the Low and Linear Low Density Polyethylene Blown Films, Journal of Plastic Film \& Sheeting, 9(3): 246-258.

3. Kuijk, E.W., Tas, P.P. and Neuteboom, P. (1999). A Rheological Model for the Prediction of PE B.F. Film Properties, J. Reinf. Plast. Comp., 18(6): 508-517.

4. Han, C.D. and Park, J.Y. (1975). Studies on Blown Film Extrusion. III. Bubble Instability, Journal of Applied Polymer Science, 19(12): 32913297.

5. Cao, B. and Campbell, G.A. (1989). Air Ring Effect on Blown Film Dynamics, Intern. Polymer Processing, 4(2): 114-118.

6. Pearson, J.R.A. and Petrie, J.S. (1970). The Flow of a Tubular Film. Part 1. Formal Mathematical Representation, J. Fluid Mech., Part 1, 40: 1-19.

7. Pearson, J.R.A. and Petrie, J.S. (1970). The Flow of a Tubular Film. Part 2. Interpretation of the Model and Discussion of Solutions, J. Fluid Mech., Part 3, 42: 609-625. 
8. Petrie, C.J.S. (1973). Memory Effect in a Non-uniform Flow, A Study of the Behaviour of a Tubular Film of Viscoelastic Fluid, Rheol. Acta, 12(2): 92-99.

9. Han, C.D. and Park, J.Y. (1975). Studies on Blown Film Extrusion. II. Analysis of the Deformation and Heat Transfer Processes, Journal of Applied Polymer Science, 19(12): 3277-3290.

10. Andre, J.-M. (1999). Modélisation Thermomécanique et Structurale du Soufflage de Gaine de Polyethylenes, These de Doctorat en Sciences et Génie des Matériaux, Ecole des Mines de Paris.

11. Laffargue, J. (2003). Etude et modelisation des instabilities du procede de soufflage de gaine, These de Doctorat en Sciences et Génie des Matériaux, Ecole des Mines de Paris.

12. Housiadas, K. and Tsamopoulos, J. (2000). Unsteady Extrusion of a Viscoelastic Annular Film. I. General Model and its Numerical Solution, J. Non-Newt. Fluid Mech., 88(3): 229-259.

13. Housiadas, K. and Tsamopoulos, J. (2000). Unsteady Extrusion of a Viscoelastic Annular Film. II. Linearized Model and its Numerical Solution, J. Non-Newt. Fluid Mech., 88(3): 303-325.

14. Yoon, K.S. and Park, C.W. (1992). Analysis of Isothermal Two-Layer Blown Film Coextrusion, Polymer Engineering and Science, 32(23): 1771-1777.

15. Gamache, E. (2004). Evaluation de la birefringence en ligne et modelisation du procede de soufflage de gaine multicouche, These en cotutelle: doctorat en genie chimique, Ecole Polytechnique de Montreal; doctorat en Sciences et genie des materiaux, Ecole des Mines de Paris.

16. Nagarajan, G. and Campbell, G.A. (1995). Experimental Determination of Heat Transfer Coefficient in Blown Film Process, ANTEC 95, pp. 162-166.

17. Petrie, C.J.S. (1975). Comparison of Theoretical Predictions with Published Experimental Measurements on the Blown Film Process, AIChE Journal, 21(2): 275-282.

18. Zeppenfeld, T. (1971). Kunstsoffe, 16(3): 147.

19. Sidiropoulos, V. and Vlachopoulos, J. (2000a). An Investigation of Venturi and Coanda Effects in Blown Film Cooling, Intern. Polym. Process, 15(1): 40-45.

20. Sidiroupoulos, V. and Vlachopoulos, J. (2000b). The Effects of Dual-orifice Air-ring Design on Blown Film Cooling, Polym. Eng. Sci., 40(7): 1611-1618.

21. Kanai, T. and White, J.L. (1985). Kinematics, Dynamics Heat Transfer and Structure Development in Tubular Film Extrusion of Polymer Melts: A Mathematical Model and Predictions, Journal of Polymer Engineering, 5(2): 135-157.

22. Menges, G. and Predohl, W.O. (1972). Heat Transfer on Blown Film and its Shrinkage Behaviour, Plastverarbeiter, 23(5): 338-344. 